\title{
A CONTROLLED TRIAL OF TWO NUCLEOSIDE ANALOGUES PLUS INDINAVIR IN PERSONS WITH HUMAN IMMUNODEFICIENCY VIRUS INFECTION AND CD4 CELL COUNTS OF 200 PER CUBIC MILLIMETER OR LESS
}

\author{
Scott M. Hammer, M.D., Kathleen E. Souires, M.D., Michael D. Hughes, Ph.D., Janet M. Grimes, M.S., \\ Lisa M. Demeter, M.D., Judith S. Currier, M.D., Joseph J. Eron, JR., M.D., Judith E. Feinberg, M.D., \\ Henry H. Balfour, JR., M.D., Lawrence R. Deyton, M.D., Jeffrey A. Chodakewitz, M.D., \\ and Margaret A. Fischl, M.D., for the AidS Clinical Trials Group 320 Study Team*
}

\begin{abstract}
Background The efficacy and safety of adding a protease inhibitor to two nucleoside analogues to treat human immunodeficiency virus type 1 (HIV-1) infection are not clear. We compared treatment with the protease inhibitor indinavir in addition to zidovudine and lamivudine with treatment with the two nucleosides alone in HIV-infected adults previously treated with zidovudine.

Methods A total of 1156 patients not previously treated with lamivudine or protease inhibitors were stratified according to CD4 cell count (50 or fewer vs. 51 to 200 cells per cubic millimeter) and randomly assigned to one of two daily regimens: $600 \mathrm{mg}$ of zidovudine and $300 \mathrm{mg}$ of lamivudine, or that regimen with $2400 \mathrm{mg}$ of indinavir. Stavudine could be substituted for zidovudine. The primary end point was the time to the development of the acquired immunodeficiency syndrome (AIDS) or death.

Results The proportion of patients whose disease progressed to AIDS or death was lower with indinavir, zidovudine (or stavudine), and lamivudine (6 percent) than with zidovudine (or stavudine) and lamivudine alone (11 percent; estimated hazard ratio, 0.50 ; 95 percent confidence interval, 0.33 to 0.76 ; $\mathrm{P}=0.001$ ). Mortality in the two groups was 1.4 percent and 3.1 percent, respectively (estimated hazard ratio, 0.43 ; 95 percent confidence interval, 0.19 to $0.99 ; \mathrm{P}=0.04)$. The effects of treatment were similar in both CD4 cell strata. The responses of CD4 cells and plasma HIV-1 RNA paralleled the clinical results.

Conclusions Treatment with indinavir, zidovudine, and lamivudine as compared with zidovudine and lamivudine alone significantly slows the progression of HIV-1 disease in patients with 200 CD4 cells or fewer per cubic millimeter and prior exposure to zidovudine. (N Engl J Med 1997;337:725-33.)
\end{abstract}

$\mathrm{P}$ ROGRESS in the field of antiretroviral therapy for human immunodeficiency virus type l (HIV-l) infection has brought the end of the zidovudine-monotherapy era, ${ }^{1-3}$ an improved understanding of the pathogenesis of HIV-1 disease ${ }^{4-9}$ demonstrations of the prognostic importance of plasma HIV-1 RNA quantification, ${ }^{10-17}$ and the availability of increasingly potent therapeutic agents. Much of this progress is linked to the introduction of the HIV-protease inhibitors, drugs that inhibit the processing of Gag and Gag-Pol polyprotein precursors and thus prevent the maturation of virions. ${ }^{18-20}$ Trials of HIV-protease inhibitors have shown beneficial effects on CD4 cell counts and plasma HIV-l RNA concentrations to a degree not previously described with approved reverse-transcriptase inhibitors. ${ }^{21-26}$ The most notable findings have involved three-drug combinations that include a potent HIV-protease inhibitor and two nucleoside an-

From Harvard Medical School, Boston (S.M.H.); the University of Alabama at Birmingham, Birmingham (K.E.S.); the London School of Hygiene and Tropical Medicine, London (M.D.H.); Harvard School of Public Health, Boston (M.D.H., J.M.G.); the University of Rochester, Rochester, N.Y. (L.M.D.); the University of Southern California, Los Angeles (J.S.C.); the University of North Carolina, Chapel Hill (J.J.E.); the University of Cincinnati, Cincinnati (J.E.F.); the University of Minnesota, Minneapolis (H.H.B.); the Division of AIDS, National Institute of Allergy and Infectious Diseases, Bethesda, Md. (L.R.D.); Merck and Co., West Point, Pa. (J.A.C.); and the University of Miami, Miami (M.A.F.). Address reprint requests to Dr. Hammer at the Division of Infectious Diseases, Beth Israel Deaconess Medical Center, I Deaconess Rd., Boston, MA 02215.

Other authors were John P. Phair, M.D. (Northwestern University), William Spreen, Pharm.D. (Glaxo-Wellcome), Louise Pedneault, M.D. (Bristol-Myers Squibb), Bach-Yen Nguyen, M.D. (Merck), and Jon C. Cook, B.Sc. (AIDS Clinical Trials Group Operations Center).

*The institutions and investigators participating in the AIDS Clinical Trials Group 320 Study are listed in the Appendix. 
alogues. Specifically, when patients previously exposed to zidovudine who had either 50 to 400 or 50 or fewer CD4 cells per cubic millimeter were treated with indinavir, zidovudine, and lamivudine, plasma HIV-1 RNA concentrations were suppressed to less than 500 copies per milliliter in 85 percent and 65 percent of patients, respectively. ${ }^{24,25}$ These findings have raised the important question of the clinical efficacy and safety of a three-drug regimen containing indinavir. We addressed that issue in this study.

\section{METHODS}

\section{Study Design and Patients}

The AIDS Clinical Trials Group 320 Study was a randomized, double-blind, placebo-controlled trial that compared the threedrug regimen of indinavir (Crixivan), open-label zidovudine (Retrovir) or stavudine (Zerit), and lamivudine (Epivir) with the two-drug regimen of zidovudine (or stavudine) and lamivudine in HIV-infected patients who had no more than 200 CD4 cells per cubic millimeter and at least three months of prior zidovudine therapy. The randomization was stratified according to the CD4 cell count obtained at the time of screening ( 50 or fewer cells per cubic millimeter as compared with 51 to 200 cells per cubic millimeter). The study was designed to enroll 1750 patients, with 40 percent of them in the stratum with 50 or fewer CD4 cells per cubic millimeter. The primary outcome measure in the assessment of efficacy was the development of a new acquired immunodeficiency syndrome (AIDS)-defining event (except when the AIDS-defining event was the development of Pneumocystis carinii pneumonia, in which case both new and recurrent events were accepted as outcome measures) or death; in the assessment of safety, the outcome measure was the occurrence of adverse events (signs, symptoms, or laboratory abnormalities) defined as severe or worse according to the grading scheme of the AIDS Clinical Trials Group. ${ }^{27}$ The secondary outcome measures studied were death and changes in CD4 cell counts and plasma HIV-I RNA concentrations.

The patients, recruited from 33 AIDS Clinical Trials Units and 7 National Hemophilia Foundation sites in the United States and Puerto Rico (see the Appendix), had to be more than 16 years old and had to have laboratory documentation of HIV-1 infection, a CD4 cell count of 200 per cubic millimeter or less within the 60 days before entry into the study, at least 3 months of prior zidovudine treatment, no more than 1 week of prior lamivudine treatment, no prior treatment with protease inhibitors, a Karnofsky performance score of at least 70 , and acceptable laboratory values. The study was approved by the institutional review boards of the participating institutions, and all the patients gave written informed consent.

The patients received open-label zidovudine $(200 \mathrm{mg}$ three times daily) and lamivudine ( $150 \mathrm{mg}$ two times daily) and were randomly assigned to receive indinavir $(800 \mathrm{mg}$ ) or matching placebo every eight hours. In the first version of the protocol, only patients who could tolerate zidovudine and who had had at least 6 months of prior zidovudine therapy were enrolled, and the substitution of stavudine for zidovudine was permitted in the event of drug-associated toxicity at any point after randomization or if clinical progression of HIV-1 disease occurred that did not fulfill the criteria for a protocol-defined AIDS event at or beyond 24 weeks of study. The dose of stavudine was $40 \mathrm{mg}$ two times daily (or $30 \mathrm{mg}$ two times daily for patients weighing less than $60 \mathrm{~kg}$ ). A protocol modification in October 1996 reduced the required prior exposure to zidovudine to at least three months and permitted patients who could not tolerate zidovudine to enter the study with stavudine substituted for zidovudine at the time of randomization. Prophylaxis for P. carinii pneumonia was mandated. Pro- phylaxis for other opportunistic infections was permitted, although the use of rifabutin was prohibited.

Patients who had verified AIDS-defining events were offered open-label indinavir therapy with the approval of the study chairs and without having their initial treatment assignments revealed. All potential AIDS-defining events were reviewed in a blinded fashion by the study chair; only those that met the criteria defined in the study protocol were included in the analysis.

\section{Monitoring and Enrollment}

The patients were followed at weeks 4,8 , and 16 and every eight weeks thereafter with a clinical assessment and routine laboratory monitoring. CD4 cell counts were determined twice at base line and at weeks 4, 8, 24, and 40. Enrollment began in January 1996. The study was reviewed twice by a data and safety monitoring board. At the second such review, on February 18, 1997, the comparison of the groups based on data on the patients randomized by January 27, 1997, showed a significant difference between groups that met the prespecified guideline for stopping the study. ${ }^{28}$ At that time, the board recommended that the accrual of patients be terminated and the study closed.

Plasma HIV-1 RNA concentrations were determined retrospectively in appropriately stored specimens from 190 randomly selected patients. These concentrations were measured twice at base line and at weeks 4, 8, 24, and 40 (Roche Amplicor HIV-1 Monitor assay)..$^{29}$

\section{Statistical Analysis}

The times to events were compared between treatment groups by Kaplan-Meier estimates, log-rank tests, and proportional-hazards models stratified according to the CD4 cell count obtained at the time of screening (50 or fewer vs. 51 to 200 cells per cubic millimeter). ${ }^{30}$ Changes in CD4 cell counts over time were compared in a mixed-effects regression model. ${ }^{31}$ An analysis of covariance adjusted for the screening CD4 cell count and the AIDS Clinical Trials Unit was used to compare changes in the CD4 cell count and the HIV-1 RNA concentration at each measurement. ${ }^{32}$ With regard to changes in HIV-1 RNA, this calculation used a regression for censored data: concentrations below the limit of quantification, 500 copies per milliliter, were censored. ${ }^{33}$ Analyses of all the variables pertaining to efficacy were performed on an intention-to-treat basis that included data on all patients randomized and all available follow-up data (including that obtained after the discontinuation of the study treatment). In the analyses of adverse events, the treatments were compared by a chi-square test; the follow-up data were censored either when a patient began receiving open-label indinavir or 56 days after the permanent discontinuation of the study treatment, whichever came first, and were restricted to patients for whom the study treatment was dispensed. All reported $\mathrm{P}$ values are two-sided. P values, estimates of differences between treatments, and 95 percent confidence intervals are unadjusted for the repeated interim analyses.

\section{RESULTS}

\section{Accrual and Characteristics of the Patients}

There were 1156 patients randomized between January 29, 1996, and January 27, 1997. Of these, 439 (38 percent) had $50 \mathrm{CD} 4$ cells or fewer per cubic millimeter and 717 (62 percent) had 51 to 200 CD4 cells per cubic millimeter. The base-line characteristics of the study patients (Table l) were well balanced between treatment groups.

\section{Duration of Follow-up and Study Treatment}

The median duration of follow-up was 38 weeks. Five percent of the patients were lost to follow-up; 


\begin{tabular}{|c|c|c|c|}
\hline \multirow[t]{2}{*}{ Characteristic } & \multirow[t]{2}{*}{$\begin{array}{l}\text { AlL PAtients } \\
(\mathrm{N}=\mathbf{1 1 5 6})\end{array}$} & \multicolumn{2}{|c|}{ CD4 Count Per Cubic Millimeter } \\
\hline & & $\begin{array}{l}\leqslant 50 \text { CELLS } \\
(\mathrm{N}=439)\end{array}$ & $\begin{array}{c}51-200 \text { CELLS } \\
(\mathrm{N}=717)\end{array}$ \\
\hline Male sex - no. (\%) & $956(83)$ & $365(83)$ & $591(82)$ \\
\hline Age $-\mathrm{yr}$ & $39 \pm 9$ & $39 \pm 8$ & $40 \pm 9$ \\
\hline $\begin{array}{l}\text { Race or ethnic group - no. (\%) } \\
\text { White, non-Hispanic } \\
\text { African American } \\
\text { Hispanic } \\
\text { Asian Pacific or other }\end{array}$ & $\begin{aligned} 598 & (52) \\
328 & (28) \\
205 & (18) \\
25 & (2)\end{aligned}$ & $\begin{array}{r}203(46) \\
142(32) \\
84(19) \\
10(2)\end{array}$ & $\begin{array}{l}395(55) \\
186(26) \\
121(17) \\
15(2)\end{array}$ \\
\hline Injection-drug use - no. (\%) & $184(16)$ & $67(15)$ & $117(16)$ \\
\hline Hemophilia — no. (\%) & $36(3)$ & $16(4)$ & $20(3)$ \\
\hline Karnofsky score $\geqslant 90-$ no. $(\%)$ & $942(81)$ & $317(72)$ & $625(87)$ \\
\hline CD 4 count - cells $/ \mathrm{mm}^{3} \dagger$ & $87 \pm 70$ & $22 \pm 24$ & $126 \pm 59$ \\
\hline HIV-1 RNA - $\log _{10}$ copies $/ \mathrm{ml} \ddagger$ & $5.0 \pm 0.6$ & $5.2 \pm 0.5$ & $4.9 \pm 0.7$ \\
\hline $\begin{array}{l}\text { Months of prior zidovudine therapy, } \\
\text { alone or in combination - median } \\
\text { ( } 25 \text { th, } 75 \text { th percentile) }\end{array}$ & $21(10,42)$ & $19(10,36)$ & $22(10,48)$ \\
\hline \multicolumn{4}{|c|}{$\begin{array}{l}\text { *Plus-minus values are means } \pm \text { SD. Because of rounding, not all columns total } 100 \text { percent. } \\
\text { †Values shown are the means of two measurements obtained at least one day apart. Values obtained } \\
\text { at screening, which had to be } \leqslant 200 \text { cells per cubic millimeter, were not included in this calculation. }\end{array}$} \\
\hline
\end{tabular}

the duration of follow-up and the percentage of patients lost to follow-up were similar in both treatment groups and both CD4-cell strata.

Ten patients did not have any study treatment. Of the remaining 1146 patients, 227 (20 percent) discontinued the study treatment prematurely, more than seven days before reaching a study end point. The proportion who discontinued the study treatment was higher in the group receiving zidovudine (or stavudine) and lamivudine (28 percent) than in the group receiving indinavir, zidovudine (or stavudine), and lamivudine (12 percent, $\mathrm{P}<0.001)$. In the stratum with $50 \mathrm{CD} 4$ cells or fewer per cubic millimeter, the proportions of patients discontinuing the study treatment in the two groups were 32 percent and 16 percent, respectively $(\mathrm{P}<0.001)$, and in the stratum with 51 to $200 \mathrm{CD} 4$ cells per cubic millimeter, these proportions were 26 percent and 9 percent $(\mathrm{P}<0.001)$. Only 4 percent of patients (10 of 227) discontinued the study treatment prematurely because of protocol-defined adverse events: 4 patients assigned to zidovudine (or stavudine) and lamivudine and 6 patients assigned to indinavir, zidovudine (or stavudine), and lamivudine. Among the premature discontinuations, 52 percent (117 of 227) were initiated by the patients, and for approximately half these patients the reasons given included a desire to seek open-label therapy with protease inhibitors, concern about the plasma HIV-1 RNA concen- tration (on the basis of determinations made outside the study), or both.

\section{Progression of Disease}

Ninety-six patients ( 8 percent $)$ had AIDS-defining events or died (Table 2). Sixty-three patients (11 percent) assigned to zidovudine (or stavudine) and lamivudine had disease progression, as compared with 33 patients ( 6 percent) assigned to indinavir, zidovudine (or stavudine), and lamivudine $(\mathrm{P}=0.001$; estimated hazard ratio, $0.50 ; 95$ percent confidence interval, 0.33 to 0.76 ) (Fig. IA). There was no significant difference in the relative effects of the two treatments between the patients with $50 \mathrm{CD} 4$ cells or fewer per cubic millimeter and the patients with 51 to 200 CD4 cells per cubic millimeter. Forty-four patients in the former stratum $(20$ percent $)$ had AIDS-defining events or died in the group assigned to zidovudine (or stavudine) and lamivudine, as compared with 23 patients (11 percent) in the group assigned to indinavir, zidovudine (or stavudine), and lamivudine ( $\mathrm{P}=0.005$; estimated hazard ratio, $0.49 ; 95$ percent confidence interval, 0.30 to 0.82 ) (Fig. 1B). In the stratum with 51 to $200 \mathrm{CD} 4$ cells per cubic millimeter, 19 patients ( 5 percent) had AIDS-defining events or died in the group assigned to zidovudine (or stavudine) and lamivudine, as compared with 10 patients ( 3 percent) in the group assigned to indinavir, zidovudine (or stavu- 


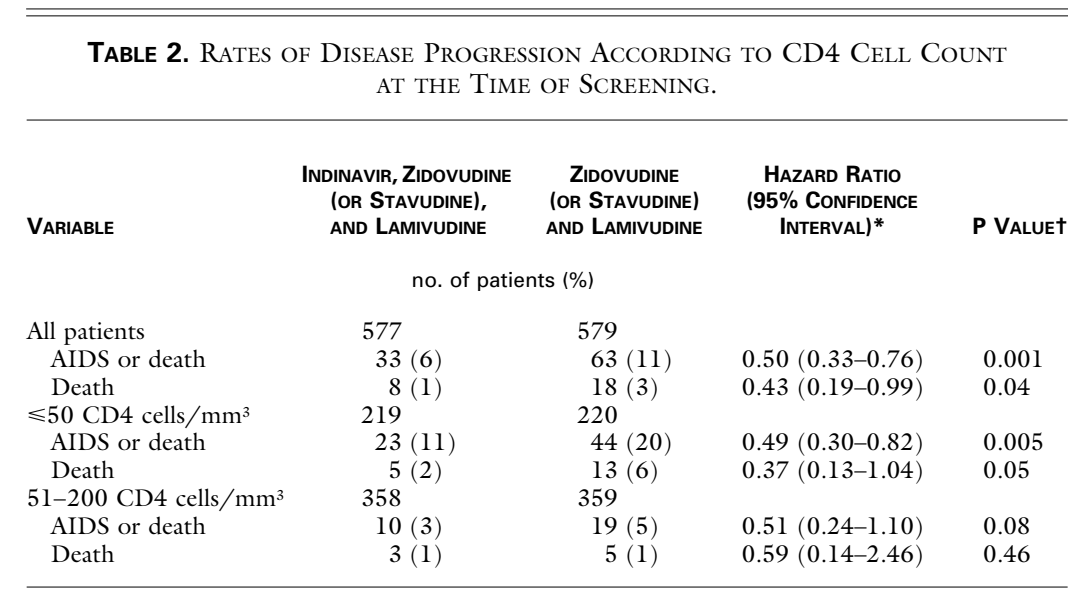

* The reference group is the group receiving zidovudine (or stavudine) and lamivudine.

†Values were calculated by the log-rank test.

dine), and lamivudine ( $\mathrm{P}=0.08$; estimated hazard ratio, $0.51 ; 95$ percent confidence interval, 0.24 to 1.10) (Fig. 1C).

Overall, 26 patients died (2.2 percent) (Table 2$)$. Eighteen patients (3.1 percent) died in the group assigned to zidovudine (or stavudine) and lamivudine, as compared with eight (1.4 percent) in the group assigned to indinavir, zidovudine (or stavudine), and lamivudine $(\mathrm{P}=0.04$; estimated hazard ratio, 0.43 ; 95 percent confidence interval, 0.19 to 0.99 ). There was no significant difference in the relative effects of the two treatments between the two strata. Among the patients with $50 \mathrm{CD} 4$ cells or fewer per cubic millimeter, 13 patients receiving only the two nucleoside analogues died ( 5.9 percent), as compared with 5 patients receiving all three drugs $(2.3$ percent; $\mathrm{P}=0.05$; estimated hazard ratio, $0.37 ; 95$ percent confidence interval, 0.13 to 1.04 ). Among the patients with 51 to 200 CD4 cells per cubic millimeter, five patients assigned to zidovudine (or stavudine) and lamivudine (1.4 percent) died, as compared with three patients assigned to indinavir, zidovudine (or stavudine), and lamivudine ( 0.8 percent).

A total of 109 of the 1156 patients (9.4 percent) were treated with stavudine instead of zidovudine before the development of an AIDS-defining event or death. None of the three patients who were initially assigned to stavudine had a protocol-defined end point. Among the 106 patients in whom stavudine was substituted for zidovudine after randomization, 3 (all in the two-nucleoside group) had AIDS-defining events, and none died.

\section{AIDS-Defining Events}

In all, there were 91 AIDS-defining events (including multiple events per patient). Sixty of these occurred among the patients assigned to receive zidovudine (or stavudine) and lamivudine, as com- pared with 31 among the patients assigned to indinavir, zidovudine (or stavudine), and lamivudine. The most common events were infections with $P$. carinii, cytomegalovirus, and Mycobacterium avium complex (constituting 25 percent, 20 percent, and 16 percent of events, respectively).

\section{Changes in CD4 Cell Counts}

Increased CD4 cell counts that persisted above base-line values were seen in both treatment groups, with superior responses in the group receiving indinavir. At weeks 4, 8, 24, and 40, the mean CD4 cell count in the patients assigned to zidovudine (or stavudine) and lamivudine increased by $27,30,18$, and 40 cells per cubic millimeter, respectively. The corresponding mean increases in the patients assigned to indinavir, zidovudine (or stavudine), and lamivudine were $46,65,91$, and 121 cells per cubic millimeter (Fig. 2A). Thus, the change at week 4 was greater by 19 cells per cubic millimeter $(\mathrm{P}<0.001)$ in the group that received indinavir, and the difference increased with time $(\mathrm{P}<0.001)$, to 36,73 , and 82 cells per cubic millimeter at weeks 8,24 , and 40 , respectively.

The responses of the CD4 cell count to treatment are shown in Figures 2B and 2C. In the group receiving zidovudine (or stavudine) and lamivudine, the early increases from base line - those at weeks 4 and 8 - were smaller in the stratum with 50 CD4 cells or fewer per cubic millimeter than in the stratum with 51 to 200 CD4 cells per cubic millimeter. However, the changes from base line in the longer term - those at weeks 24 and 40 - were similar in the two strata. Exploratory analyses of the CD4 cell counts in the two treatment groups when the data were censored at the times patients changed from the treatment to which they were initially assigned showed increases from base line that were similar to those in the intention-to-treat analyses at weeks 4 , 
All Patients $(\mathrm{N}=1156)$
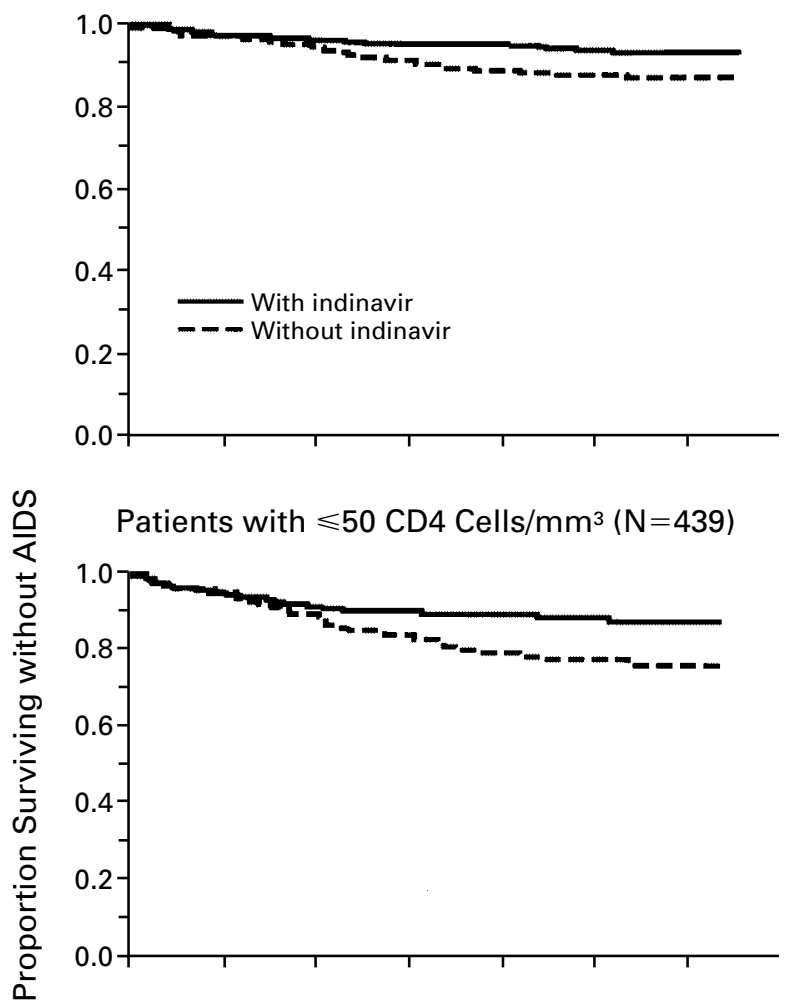

Patients with $51-200 \mathrm{CD} 4$ Cells $/ \mathrm{mm}^{3}$ ( $\left.\mathrm{N}=717\right)$

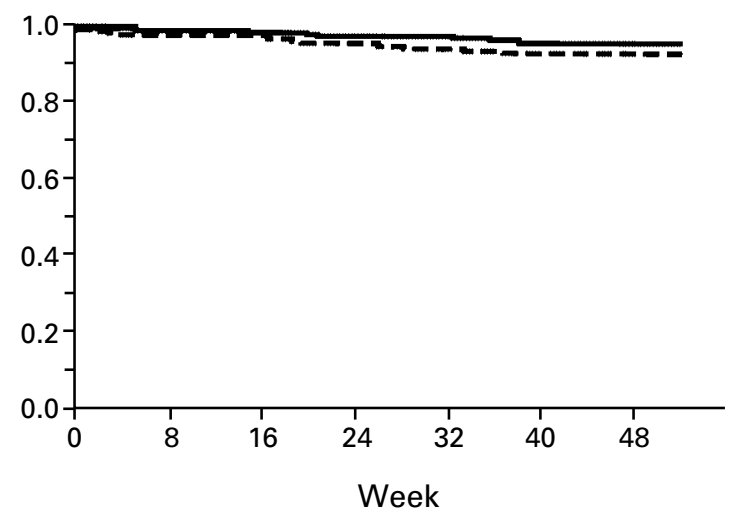

Figure 1. Kaplan-Meier Estimates of the Proportion of Patients Who Did Not Reach the Primary Study End Point of AIDS or Death.

8 , and 24 (data not shown). At week 40, the difference between the two treatment groups was smaller in the intention-to-treat analysis than in the censored analysis (difference in mean change, 82 vs. 115 cells per cubic millimeter), suggesting that the difference may have been reduced by the greater proportion of subjects who changed treatment in the group receiving zidovudine (or stavudine) and lamivudine.
All Patients
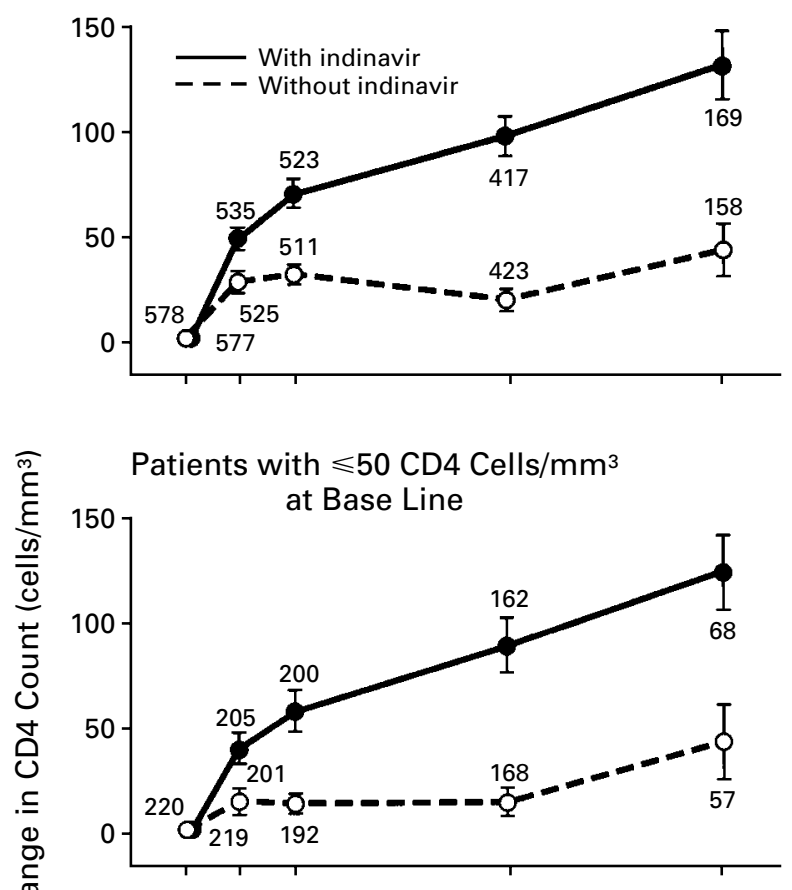

$\frac{\sqrt{0}}{\circlearrowright}$

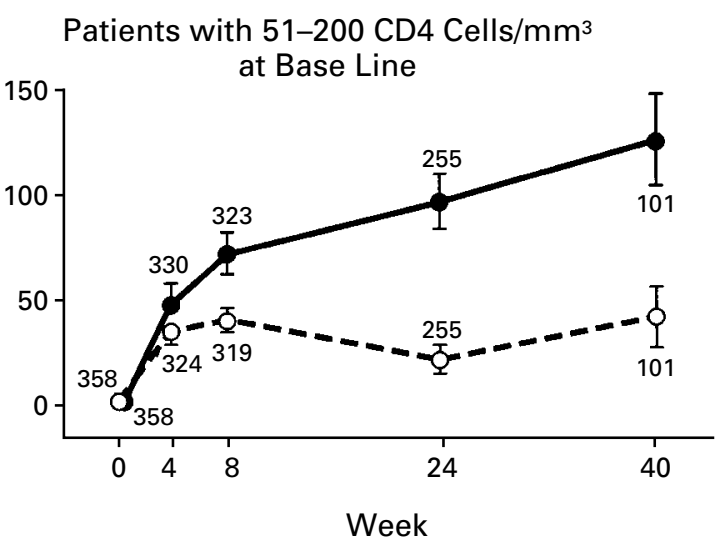

Figure 2. Mean Changes from Base Line in the CD4 Cell Count. The number of patients who could be evaluated at each time point is shown. Bars indicate 95 percent confidence intervals.

\section{Changes in Plasma HIV-1 RNA Concentrations}

The responses of the plasma HIV-1 RNA concentrations to treatment were studied in 190 randomly selected patients. There were persistent decreases from the base-line values in both treatment groups, with significantly better responses in the group whose treatment included indinavir $(\mathrm{P}<0.001$ in an area-under-the-curve analysis). At weeks 4, 8, 24, and 40 , the mean decreases in plasma HIV-l RNA 
in the group receiving zidovudine (or stavudine) and lamivudine were $0.9,0.6,0.6$, and $1.0 \log _{10}$ copies per milliliter, respectively. The corresponding decreases in the group receiving indinavir, zidovudine (or stavudine), and lamivudine were 1.8, 2.3, 2.8, and $2.1 \log _{10}$ copies per milliliter (Fig. 3A). The changes from base line were significantly greater at each time point in the group treated with indinavir $(\mathrm{P}<0.001$ at weeks 4,8 , and $24 ; \mathrm{P}=0.007$ at week $40)$. At week 24 , the proportion of patients with plasma HIV-1 RNA concentrations of less than 500 copies per milliliter was 9 percent in the two-nucleoside group, as compared with 60 percent in the group treated with indinavir.

The plasma HIV-l RNA responses according to the CD4 cell count are shown in Figures $3 \mathrm{~B}$ and $3 \mathrm{C}$. In the patients with $50 \mathrm{CD} 4$ cells or fewer per cubic millimeter, the decreases in plasma HIV-l RNA appeared to be smaller than those in the patients with 51 to 200 CD4 cells per cubic millimeter. However, conclusions about stratum-specific plasma HIV-1 RNA responses need to be made cautiously because of the small numbers of patients followed through week 40 .

\section{Adverse Events}

The proportion of patients with signs and symptoms that were severe (grade 3 ) or worse (grade 4) in the group receiving zidovudine (or stavudine) and lamivudine was 18 percent, as compared with 21 percent in the group receiving indinavir, zidovudine (or stavudine), and lamivudine $(\mathrm{P}=0.17)$. The most common symptoms were nonspecific discomfort, malaise, fever, headache, and nausea and vomiting, with no difference in the reporting of symptoms between treatment groups.

The proportion of patients with severe laboratory abnormalities or worse in the group receiving zidovudine (or stavudine) and lamivudine was 26 percent, as compared with 21 percent in the group receiving indinavir, zidovudine (or stavudine), and lamivudine $(\mathrm{P}=0.06)$. This difference primarily reflected a difference between the groups in the incidence of neutropenia ( 15 percent and 5 percent, respectively; $\mathrm{P}<0.001$ ). In contrast, the proportion of patients with hyperbilirubinemia was 1 percent in the two-nucleoside group, as compared with 6 percent in the group treated with indinavir $(\mathrm{P}<0.001)$, a finding compatible with the known elevation of indirect bilirubin associated with the use of indinavir. Two percent of the patients in each treatment group had hyperglycemia.

Five patients receiving zidovudine (or stavudine) and lamivudine ( 1 percent) had episodes of renal colic or nephrolithiasis (irrespective of grade), as compared with 21 patients receiving indinavir, zidovudine (or stavudine), and lamivudine (4 percent, $\mathrm{P}=0.001)$. Three of the five patients in the two-

\section{All Patients in Sample}

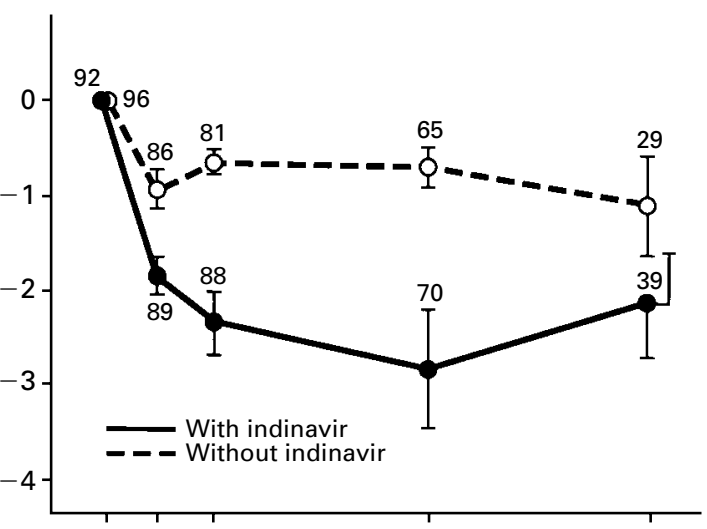

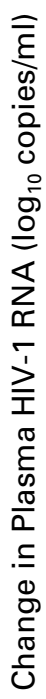

\section{Patients with $\leqslant 50$ CD4 Cells $/ \mathrm{mm}^{3}$}

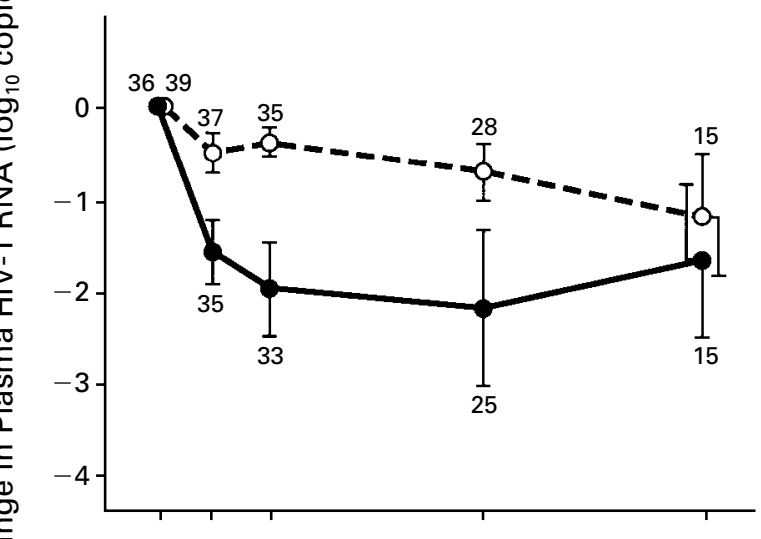

Patients with 51-200 CD4 Cells/mm³

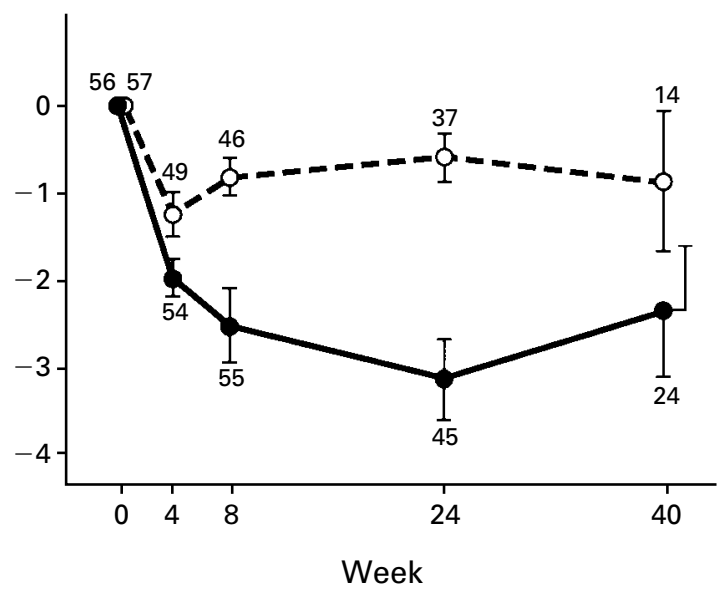

Figure 3. Mean Change from Base Line in the Plasma HIV-1 RNA Concentration.

For this analysis, 190 patients were randomly selected and their HIV-1 RNA concentrations were studied. The number of patients who could be evaluated at each time point is shown. Bars indicate 95 percent confidence intervals. 
nucleoside group in whom renal colic or nephrolithiasis developed had that condition after discontinuing the study treatment and starting open-label indinavir treatment.

Five new diagnoses of diabetes mellitus were recorded: two in the two-nucleoside group and three in the group treated with indinavir.

\section{DISCUSSION}

This study showed the clinical superiority of the three-drug regimen containing indinavir over the two-nucleoside combination in patients previously treated with zidovudine who had CD4 cell counts of 200 per cubic millimeter or less. The proportion of patients whose disease progressed to AIDS or death was reduced from 11 percent to 6 percent by the three-drug combination, a 50 percent reduction $(\mathrm{P}=0.001)$. The hazard ratios in the study patients as a whole $(0.50)$, those with CD4 cell counts of 50 per cubic millimeter or less (0.49), and those with counts of $5 \mathrm{l}$ to 200 per cubic millimeter $(0.5 \mathrm{l})$ were very similar, suggesting that the effect of treatment was similar across the study population, although the possibility of differential effects cannot be ruled out. Mortality, low in both groups, was reduced from 3.1 percent to 1.4 percent with the three-drug regimen $(\mathrm{P}=0.04)$. Thus, there was evidence of a reduction in mortality that was consistent with the reduced risk of progression to the primary outcome measure of AIDS or death.

The rate of loss to follow-up in this study was low ( 5 percent), and the overall rate of premature discontinuation of treatment was moderate $(20$ percent). Seventy-nine percent of the 96 AIDS-defining events or deaths occurred while the patients were receiving the study treatment or within seven days of its discontinuation. Although rates of withdrawal from treatment differed between the two study groups, the tendency for patients who withdrew prematurely from the two-nucleoside group to seek treatment with protease inhibitors would tend to narrow the differences between the groups in rates of disease progression and therefore should not affect the conclusions of the study. Conversely, when a study is terminated early because a stopping guideline is used, differences between the treatment groups tend to be overestimated because of random variation. ${ }^{34}$ However, it is impossible to determine the relative magnitude of these effects.

These findings confirm on the basis of clinical end points the results of earlier trials of the combination of indinavir, zidovudine, and lamivudine in patients previously treated with zidovudine, trials that showed that the three-drug combination produces superior responses in plasma HIV-1 RNA concentrations and CD4 cell counts. ${ }^{24,25}$ The suppression of plasma HIV-I RNA to unquantifiable levels in the majority of subjects with this drug combination is accompa- nied by greater suppression of HIV-I RNA expression in lymphoid tissue ${ }^{35}$ and may prevent the emergence of resistance - factors that may add to the clinical benefit now established for this regimen. Our study also found superior responses of CD4 cells and plasma HIV-1 RNA with the three-drug regimen.

We chose the combination of zidovudine and lamivudine as the control treatment because of the unique interactions between these two agents with respect to mutations conferring resistance, the results of phase 2 trials, the tolerance associated with the regimen, and its widespread use in clinical practice. ${ }^{36-40}$ The clinical benefit of lamivudine when that drug is added to previously available nucleoside analogues to treat patients with 25 to $250 \mathrm{CD} 4$ cells per cubic millimeter was recently confirmed in the CAESAR trial, in which the risk of AIDS or death was reduced by approximately 50 percent. ${ }^{41}$ In the control group in our study, there was a relatively low rate of disease progression, as well as a moderate increase in the CD4 cell count and a decline in plasma HIV-l RNA; these persisted throughout the study, even though it is now recognized that simply adding lamivudine to a preexisting regimen is not a standard clinical approach. The strength of the control group in this study is also an important difference between this study and previously reported studies of other HIV-protease inhibitors that have assessed clinical end points. ${ }^{42,43}$ In the Abbott M94247 trial, ritonavir or placebo was added to stable prior nucleoside-analogue therapy or no therapy. ${ }^{42}$ In the Hoffmann-La Roche NV14256 trial, a regimen of saquinavir plus zalcitabine was compared with zalcitabine monotherapy. ${ }^{43}$ In the context of these other trials, our study makes it clear that more potent therapies, now represented by three-drug regimens containing a protease inhibitor, are preferable in patients with advanced disease. The durability of the clinical benefit conferred by indinavir as part of a three-drug regimen has not been fully defined, however.

Improving the use of the currently approved agents to treat HIV-l infection, and the promising drugs on the clinical horizon, ${ }^{44-46}$ in the management of HIV-l disease remains a challenge. ${ }^{47}$ However, this study supports the view that employing well-tolerated regimens of increasing potency will translate into greater clinical benefits for patients with HIV-1 infection.

Supported in part by the AIDS Clinical Trials Group, National Institute of Allergy and Infectious Diseases; by the General Clinical Research Center units funded by the National Center for Research Resources; and by Merck and Co. (for institutions enrolling more than 30 patients).

Drs. Hammer, Squires, Hughes, Demeter, Currier, Eron, Feinberg, Balfour, Fischl, and Phair have served as ad hoc consultants for, or received honorariums or research grants from, one or more of the pharmaceutical firms whose products were studied (Merck, Glaxo-Wellcome, and BristolMyers Squibb). 


\section{APPENDIX}

The following institutions and investigators participated in the AIDS Clinical Trials Group 320 Study: University of North Carolina - T. Lane and J. Horton; University of Cincinnati - D. Neumann and B. Letcher; University of Puerto Rico - G. Vazquez, M. Cruz-Ortiz, and I. Lopes; University of Minnesota - C. Kumekawa, R. Schut, and S. Swindells; Washington University - P. Tebas, W. Powderly, and A. Slack; Ohio State University College of Medicine - M. Para, R. Fass, and J. Neidig; Northwestern University - J. Pulvirenti and J. Pottage, Jr.; University of Alabama and Emory University - J. Lennox and K. Tamburello; New York University Medical Center and Bellevue Hospital - R. Gulick, J. Dowling, and M. Laverty; University of Miami - E. Scerpella and A. Rodriguez; University of Texas at Galveston - R. Pollard, S. Hausrath, and M. Pickthall; Case Western Reserve University - B. Gripshover, H. Valdez, and M. Chance; Howard University - R. Delapenha, J. McNeil, and Y. Butler; Harvard University and Boston Medical Center - L. Jackson-Pope and T. Cooley; University of Rochester - R. Hewitt and C. Greisberger; University of California, Los Angeles - R. Mitsuyasu, M. Guerrero, and P. Miller; Indiana University Hospital - K. Fife, H. Nixon, and D. Heise; Meharry Medical College and Vanderbilt University Medical Center - M.A. South, D. Haas, and S. Raffanti; Duke University - C. Hicks, P. Robinson, and K. Shipp; University of California, San Diego - C. Fegan, T.-C. Meng, and S. Little; Johns Hopkins University - R. Becker, M. Higgins, L. Apuzzo, and J.B. Jackson; Mount Sinai Medical Center - P. Gerits, H. Mendoza, and D. Mildvan; University of Pennsylvania - R.R. MacGregor, I. Matozzo, and E. McCann; University of Southern California - M. Dube and C. Olsen; University of Colorado - D. Kuritzkes, B. Putnam, and D. Torre; Tulane University and Louisiana State University - J. Lertora, R. Clark, and M. Beilke; University of Hawaii - S. Souza, M. Millard, and L. Oshita; Stanford University - T. Merigan, Jr., J. Fessel, and D. Israelski; Memorial Sloan-Kettering Cancer Center - M. Giordano, P. Ristau, and M. Granville; University of Washington, Seattle - A. Collier, R. Vasquez, B. Royer, and R. Coombs; New York University Medical Center and Bellevue Hospital (pediatric site) - W. Borkowsky, S. Chandwani, and M. Minter; Columbus Children's Hospital - M. Brady, J. Hunkler, and C. Callaway; Medical University of South Carolina - G. Johnson and E. Matters; $\mathrm{Na}$ tional Hemophilia Foundation - T. Coates, T. Hofstra, W.-Y. Wong, E. Eyster, S. Seremetis, C. Kessler, S. Stabler, W. Hanna, C. Leissenger, J. Gill, P. Timmons, W.K. Hoots, and M. Cantini; Division of AIDS, National Institute of Allergy and Infectious Diseases - J. Ioannidis and A. Martinez; Statistical and Data Management Center - K. Kazial; Harvard School of Public Health - S.-H. Liou; Community Constituency Group H. Chang; Bristol-Myers Squibb - J. Skovronski and L. Dunkle; Merck and Co. - A. Meibohm.

\section{REFERENCES}

1. Hammer SM, Katzenstein DA, Hughes MD, et al. A trial comparing nucleoside monotherapy with combination therapy in HIV-infected adults with CD4 cell counts from 200 to 500 per cubic millimeter. N Engl J Med 1996;335:1081-90

2. The Delta Coordinating Committee. Delta: a randomised double-blind controlled trial comparing combinations of zidovudine plus didanosine or zalcitabine with zidovudine alone in HIV-infected individuals. Lancet 1996;348:283-91.

3. Englund JA, Baker CJ, Raskino C, et al. Zidovudine, didanosine, or both as the initial treatment for symptomatic HIV-infected children. N Engl J Med 1997;336:1704-12.

4. Wei $X$, Ghosh SK, Taylor ME, et al. Viral dynamics in human immunodeficiency virus type 1 infection. Nature 1995;373:117-22

5. Ho DD, Neumann AU, Perelson AS, Chem W, Leonard JM, Markowitz M. Rapid turnover of plasma virions and CD4 lymphocytes in HIV-1 in fection. Nature 1995;373:123-6.

6. Perelson AS, Neumann AU, Markowitz M, Leonard JM, Ho DD. HIV 1 dynamics in vivo: virion clearance rate, infected cell life-span, and viral generation time. Science 1996;271:1582-6.

7. Havlir DV, Richman DD. Viral dynamics of HIV: implications for drug development and therapeutic strategies. Ann Intern Med 1996;124:984-94 8. Haase AT, Henry K, Zupancic M, et al. Quantitative image analysis of HIV-l infection in lymphoid tissue. Science 1996;274:985-9.

9. Fauci AS. Host factors and the pathogenesis of HIV-induced disease. Nature 1996;384:529-34.

10. Katzenstein DA, Hammer SM, Hughes MD, et al. The relation of virologic and immunologic markers to clinical outcomes after nucleoside therapy in HIV-infected adults with 200 to 500 CD4 cells per cubic millimeter. N Engl J Med 1996;335:1091-8.

11. Mellors JW, Kingsley LA, Rinaldo CR Jr, et al. Quantitation of HIV1 RNA in plasma predicts outcome after seroconversion. Ann Intern Med $1995 ; 122: 573-9$.
12. Mellors JW, Rinaldo CR Jr, Gupta P, White RM, Todd JA, Kingsley LA. Prognosis in HIV-1 infection predicted by the quantity of virus in plasma. Science 1996;272:1167-70.

13. Mellors JW, Munoz A, Giorgi JV, et al. Plasma viral load and CD4+ lymphocytes as prognostic markers of HIV-1 infection. Ann Intern Med 1997;126:946-54

14. Welles SL, Jackson JB, Yen-Lieberman B, et al. Prognostic value of plasma human immunodeficiency virus type 1 (HIV-1) RNA levels in patients with advanced HIV-1 disease and with little or no zidovudine ther apy. J Infect Dis 1996;174:696-703.

15. Coombs RW, Welles SL, Hooper C, et al. Association of plasma human immunodeficiency virus type 1 RNA level with risk of clinical progression in patients with advanced infection. J Infect Dis 1996;174:704-12.

16. Hughes MD, Johnson VA, Hirsch MS, et al. Monitoring plasma HIV 1 RNA levels in addition to CD4+ lymphocyte count improves assessment of antiretroviral therapeutic response. Ann Intern Med 1997;126:929-38. 17. O'Brien WA, Hartigan PM, Daar ES, Simberkoff MS, Hamilton JD, The VA Cooperative Study Group on AIDS. Changes in plasma HIV RNA levels and CD4+ lymphocyte counts predict both response to antiretroviral therapy and therapeutic failure. Ann Intern Med 1997;126:939-45.

18. Kohl NE, Emini EA, Schleif WA, et al. Active human immunodeficiency virus protease is required for viral infectivity. Proc Natl Acad Sci U S A 1988;85:4686-90.

19. Peng C, Ho BK, Chang TW, Chang NT. Role of human immunode ficiency virus type 1 -specific protease in core protein maturation and viral infectivity. J Virol 1989;63:2550-6.

20. Seelmeier S, Schmidt H, Turk V, von der Helm K. Human immunodeficiency virus has an aspartic-type protease that can be inhibited by pepstatin A. Proc Natl Acad Sci U S A 1988;85:6612-6.

21. Danner SA, Carr A, Leonard JM, et al. A short-term study of the safety, pharmacokinetics, and efficacy of ritonavir, an inhibitor of HIV-1 protease. N Engl J Med 1995;333:1528-33.

22. Markowitz $M$, Saag $M$, Powderly WG, et al. A preliminary study of ritonavir, an inhibitor of HIV-l protease, to treat HIV-1 infection. N Engl J Med 1995;333:1534-9.

23. Stein D, Drusano G, Steigbigel R, et al. Two year follow-up of patients treated with indinavir $800 \mathrm{mg} \mathrm{q} 8 \mathrm{~h}$. In: Program and abstracts of the Fourth Conference on Retroviruses and Opportunistic Infections, Wash ington, D.C., January 22-26, 1997:100. abstract.

24. Gulick RM, Mellors JW, Havlir D, et al. Treatment with indinavir, zidovudine, and lamivudine in adults with human immunodeficiency virus infection and prior antiretroviral therapy. N Engl J Med 1997;337:734-9. 25. Hirsch M, Protocol 039 (Indinavir) Study Group, Meibohm A, Rawlins $\mathrm{S}$, Leavitt R. Indinavir in combination with zidovudine and lamivudine in ZDV-experienced patients with CD4 cell counts $\leqslant 50$ cells $/ \mathrm{mm}^{3}$. In: Program and abstracts of the Fourth Conference on Retroviruses and Opportunistic Infections, Washington, D.C., January 22-26, 1997:207. abstract. 26. Powderly W, Sension M, Conant M, Stein A, Clendeninn N. The efficacy of Viracept (nelfinavir mesylate, NFV) in pivotal phase II/III double-blind randomized controlled trials as monotherapy and in combination with d4T or AZT/3TC. In: Program and abstracts of the Fourth Conference on Retroviruses and Opportunistic Infections, Washington, D.C., January $22-26,1997: 132$. abstract.

27. Division of AIDS. Division of AIDS table for grading severity of adult adverse experiences. Rockville, Md.: National Institute of Allergy and Infectious Diseases, 1996.

28. Peto R, Pike MC, Armitage $P$, et al. Design and analysis of randomized clinical trials requiring prolonged observation of each patient. I. Introduction and design. Br J Cancer 1976;34:585-612.

29. Mulder J, McKinney N, Christopherson C, Sninsky J, Greenfield L, Kwok S. Rapid and simple PCR assay for quantitation of human immunodeficiency virus type 1 RNA in plasma: application to acute retroviral infection. J Clin Microbiol 1994;32:292-300.

30. Kalbfleisch JD, Prentice RL. The statistical analysis of failure time data. New York: John Wiley, 1980.

31. Laird NM, Ware JH. Random-effects models for longitudinal data. Bi ometrics 1982;38:963-74.

32. Pocock SJ. Clinical trials: a practical approach. Chichester, England: John Wiley, 1983

33. The Lifereg procedure. In: SAS/STAT user's guide. 4th ed. Cary, N.C.: SAS Institute, 1989:997-1025.

34. Hughes MD, Pocock SJ. Stopping rules and estimation problems in clinical trials. Stat Med 1988;7:1231-42.

35. Wong JK, Gunthard HF, Havlir DV, et al. Reduction of HIV in blood and lymph nodes after potent antiretroviral therapy. In: Program and abstracts of the Fourth Conference on Retroviruses and Opportunistic Infections, Washington, D.C., January 22-26, 1997:207. abstract.

36. Larder BA, Kemp SD, Harrigan PR. Potential mechanism for sustained antiretroviral efficacy of AZT-3TC combination therapy. Science 1995; 269:696-9. 
37. Eron JI, Benoit SL, Jemsek J, et al. Treatment with lamivudine, zidovudine, or both in HIV-positive patients with 200 to $500 \mathrm{CD} 4+$ cells pe cubic millimeter. N Engl J Med 1995;333:1662-9.

38. Katlama C, Ingrand D, Loveday C, et al. Safety and efficacy of lamivudine-zidovudine combination therapy in antiretroviral-naive patients: a randomized controlled comparison with zidovudine monotherapy. JAMA 1996;276:118-25.

39. Staszewski S, Loveday C, Picazo JJ, et al. Safety and efficacy of lamivudine-zidovudine combination therapy in zidovudine-experienced patients: a randomized controlled comparison with zidovudine monotherapy JAMA 1996;276:111-7.

40. Bartlett JA, Benoit SL, Johnson VA, et al. Lamivudine plus zidovudine compared with zalcitabine plus zidovudine in patients with HIV infection: a randomized, double-blind, placebo-controlled trial. Ann Intern Med 1996;125:161-72.

41. CAESAR Coordinating Committee. Randomised trial of addition of lamivudine or lamivudine plus loviride to zidovudine-containing regimens for patients with HIV-l infection: the CAESAR trial. Lancet 1997;349: 1413-21.

42. Cameron DW, Heath-Chiozzi M, Kravcik S, et al. Prolongation of life and prevention of AIDS complications in advanced HIV immunodeficiency with ritonavir: update. In: Volume 1 of the Abstracts of the XI International Conference on AIDS, Vancouver, B.C., July 7-12, 1996:24. abstract.
43. Salgo $M$, Beattie $D$, Bragman $K$ et al Saquinavir (Invirase, SQV) vs, HIVID (zalcitabine, ddC) vs. combination as treatment for advanced HIV infection in patients discontinuing/unable to take retrovir (zidovudine

ZDV). In: Volume 1 of the Abstracts of the XI International Conference on AIDS, Vancouver, B.C., July 7-12, 1996:24. abstract.

44. Harrigan R, Stone C, Griffin P, et al. Antiretroviral activity and resistance profile of the carbocyclic nucleoside HIV reverse transcriptase inhibitor 1592U89. In: Program and abstracts of the Fourth Conference on Retroviruses and Opportunistic Infections, Washington, D.C., January 22 26, 1997:67. abstract.

45. Schooley RT, l41W94 International Study Group. Preliminary data from a phase I/II study on the safety and antiviral efficacy of the combination of 141W94 plus 1592U89 in HIV-infected patients with 150 to 400 CD $4+$ cells $/ \mathrm{mm}^{3}$. In: Program and abstracts of the Fourth Conference on Retroviruses and Opportunistic Infections, Washington, D.C., January 22-26, 1997:206. abstract.

46. Ruiz N, DuPont Merck Study Group. A double-blind pilot study to evaluate the antiretroviral activity, tolerability of DMP 266 in combination with indinavir (cohort III). In: Program and abstracts of the Fourth Conference on Retroviruses and Opportunistic Infections, Washington, D.C., January 22-26, 1997:206. abstract.

47. Carpenter CCJ, Fischl MA, Hammer SM, et al. Antiretroviral therapy for HIV infection in 1997: updated recommendations of the International AIDS Society-USA panel. JAMA 1997;77:1962-9. 